www.jmscr.igmpublication.org

Impact Factor 5.84

Index Copernicus Value: 71.58

ISSN (e)-2347-176x ISSN (p) 2455-0450

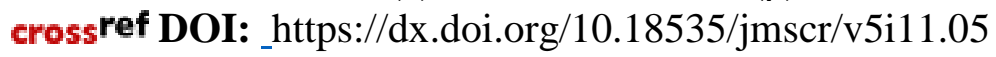

Journal Of Medical Science And Clinical Research

IGM Publication

An Official Publication of IGM Publication

\title{
Comparison of Clinicopathologic Features of Colonic Malignancies between Patients Aged below 50 and Patients aged above 50 Years
}

\author{
Authors \\ Joshinth Joseph ${ }^{1}$, Abhilash Kumar ${ }^{2}$, Manoj Thillai ${ }^{3}$, Surendran Paramasivam ${ }^{4}$, \\ Naveen Alexander ${ }^{5}$ \\ ${ }^{1}$ Department of General Surgery, Sri Ramachandra University, Porur, Chennai India \\ Email: joshinth90@gmail.com \\ ${ }^{2}$ Department of General Surgery, Sri Ramachandra University, Porur, Chennai, India \\ Email:dr.k.abhilash@gmail.com \\ ${ }^{3}$ Department of General Surgery, Sri Ramachandra University, Porur, Chennai, India \\ Email: prion57@gmail.com \\ ${ }^{4}$ Department of General Surgery, Sri Ramachandra University, Porur, Chennai, India \\ Email:drsuru@yahoo.com \\ ${ }^{5}$ Department of General Surgery, Sri Ramachandra University, Porur, Chennai, India \\ Email: naveenalexander@yahoo.co.in
}

\begin{abstract}
The incidence of colon cancer is low in India. More than $70 \%$ of colonic cancers occur in people aged 50 or older. However, colonic cancer appears to be increasing among younger patients. This study was done to compare and analyze the differences in clinical \& pathological factors of colonic malignancies occurring in young patients ( $<50$ years) and old patients ( $>50$ years). The study showed male predominance within both groups (72\% \& 80\%). Abdomen pain \& altered bowel habits and abdomen pain with generalized weakness \& anaemia were common presenting symptoms. Family history was an important predisposing factor in younger group (24\%). Presentation as acute emergency was more common in younger group when compared to older group (36\% \& 20\%). The younger group had more of left sided malignancy with poorly differentiated variety of carcinoma whereas it was evenly distributed in the older group. The time period between onset of symptoms and diagnosis was 2.4 months in younger group whereas 5.92 months in older group. Younger group tend to have more aggressive malignancy with poorer pathologic findings, and if detected early can have better overall survival rates.
\end{abstract}

Keywords: CarcinomaColon Malignancy Older Patients Younger.

\section{Introduction}

Colonic cancer is one of the commonest malignant tumours worldwide and represents an important cause of cancer-related death.

The incidence of colon cancer is low in India. According to a recent epidemiologic study, the incidence rates in eight population registries vary from 3.7 to $0.7 / 100,000$ among men and 3 to $0.4 / 100,000$ among women. The likelihood of colonic cancer diagnosis increases progressively form age 40, rising sharply after age 50. More than $70 \%$ colonic cancer cases occur in people 
aged 50 and above. However colonic cancer appears to be increasing among younger persons.

Invasive colonic cancer is preventable disease. Early detection through widespread screening programs is the most important factor in the recent decline of colorectal cancer deaths in developed countries. In the past decade, an unprecedented advance in systemic therapy for colonic cancer has dramatically improved outcome for patients with metastatic disease. Though surgery remains the definitive modality of treatment, these new agents will like translate into improved cure rates in early stage disease (stage II \& III) and prolonged survival in those with stage IV disease. Hence this specific study was aimed at comparing the various clinical and pathological factors of colonic malignancies presenting in young patients ( $<50$ Years) and older patients ( $>50$ Years) and to identify the differences on the basis of the patient's age.

\section{Materials and Methods}

A total of 68 patients diagnosed as colon cancer were included in the study, between the timeperiod from April 2013 to September 2015. Patients who underwent surgery were included in the study, which was 50. Around 18 patients were excluded for various reasons like not fit for surgery, not willing for surgery and those who went against medical advice. Patients were divided into two groups based on the age at diagnosis. Group-A patients aged 50 years \& less, and Group-B patients aged more than 50 years. Surgical treatment was curative when there was macroscopic resection of all malignant tissue and no microscopic evidence of surgical margin positivity. Post-operative mortality was defined as death within 30 days of surgery. Descriptive statistics were calculated for all variables using chi-square test. Level of significance $p<0.05$ was used. Analysis done using the SPSS 14.0 statistical package. Factors analyzed were sex, time duration for onset of symptoms, chief complaints at presentation, family \& medical history, complication at presentation, pathological tumour site \& configuration, Histopathological examination (HPE) grade, Staging and type of surgery.

\section{Results}

The study showed a male predominance in the disease occurrence within both groups (72\% and $80 \%$ ). Abdomen pain, altered bowel habits and abdomen pain with anaemia and weakness were the commonest presenting symptoms (36\% vs $32 \%$ ) whereas altered bowel habits was the predominant symptom in older group (52\%) (Table 1). Family history such as colonic malignancies, familial adenomatous polyposis, and hereditary non-polyposis colorectal cancer were present in $24 \%$ of the younger group, whereas it was only $12 \%$ in the older group.

Medical history of Diabetes \& hypertension, coronary artery disease and inflammatory bowel disease were present in older group more commonly than younger group. In the younger group, $36 \%$ of patients presented with emergency obstruction whereas only $20 \%$ of older patients presented with obstruction (Figure 1). The site of tumour varied widely, $72 \%$ of younger group had left sided colonic malignancy \& $28 \%$ right sided colonic malignancy, but the older group had an even distribution of $56 \%$ right sided and $44 \%$ left sided colonic malignancy (Figure 2).

Ulcero-proliferative type of growth was the most common type of tumour configuration in both groups. Tumour grading showed poorly differentiated high grade tumours to be more common in younger group (44\%) and moderately differentiated tumours common in older groups $(56 \%)$ (Table 2). Adenocarcinoma was the commonest variety in both the groups $(64 \%$ \& $72 \%$ ). Tumour node metastasis (TNM) staging showed T2NOM0 \& T3NOM0 equally in the younger group. Similarly T2N0M0 and T3N1M0 was almost equal in older group. Metastasis was noted only in $4 \%$ of patients in younger group whereas it was seen in $20 \%$ patients in the older group. 
Curative left hemicolectomy and Palliative Hartmann's procedure were equally done in the younger group ( $32 \%$ each), but more number of curative right hemicolectomy done in the older group (40\%) (Figure 3). Post-operative complications were $56 \%$ in younger group and
$40 \%$ in the older group. Tumour recurrence was noted in $12 \%$ of younger group whereas only in $4 \%$ of older group. The mean time duration between onset of symptoms and diagnosis was 2.4 months in younger group and 5.92 months in older group.

Table 1.

\begin{tabular}{|c|c|c|c|c|c|}
\hline & & & \multicolumn{2}{|c|}{ Group } & \multirow[b]{2}{*}{ Total } \\
\hline & & & $\leq 50$ Years & $>50$ Years & \\
\hline \multirow{6}{*}{$\begin{array}{l}\text { Chief } \\
\text { Complaint }\end{array}$} & Abdomen pain, altered & Count & 9 & 13 & 22 \\
\hline & bowel habits & $\%$ within Group & $36.0 \%$ & $52.0 \%$ & $44.0 \%$ \\
\hline & Abdomen pain & Count & 8 & 7 & 15 \\
\hline & $\begin{array}{l}\text { generalized weakness } \\
\text { and anaemia }\end{array}$ & $\%$ within Group & $32.0 \%$ & $28.0 \%$ & $30.0 \%$ \\
\hline & $\begin{array}{l}\text { Obstipation and vomiting } \\
\text { and abdomen pain }\end{array}$ & $\begin{array}{l}\text { Count } \\
\% \text { within Group }\end{array}$ & $\begin{array}{r}6 \\
24.0 \%\end{array}$ & $\begin{array}{r}5 \\
20.0 \%\end{array}$ & $\begin{array}{r}11 \\
22.0 \%\end{array}$ \\
\hline & $\begin{array}{l}\text { Faecal vomiting } \\
\text {, abdomen pain, anaemia }\end{array}$ & $\begin{array}{l}\text { Count } \\
\% \text { within Group }\end{array}$ & $\begin{array}{r}2 \\
8.0 \%\end{array}$ & $\begin{array}{r}0 \\
.0 \% \\
\end{array}$ & $\begin{array}{r}2 \\
4.0 \% \\
\end{array}$ \\
\hline \multirow[t]{2}{*}{ Total } & & Count & 25 & 25 & 50 \\
\hline & & $\%$ within Group & $100.0 \%$ & $100.0 \%$ & $100.0 \%$ \\
\hline
\end{tabular}

Figure 1.

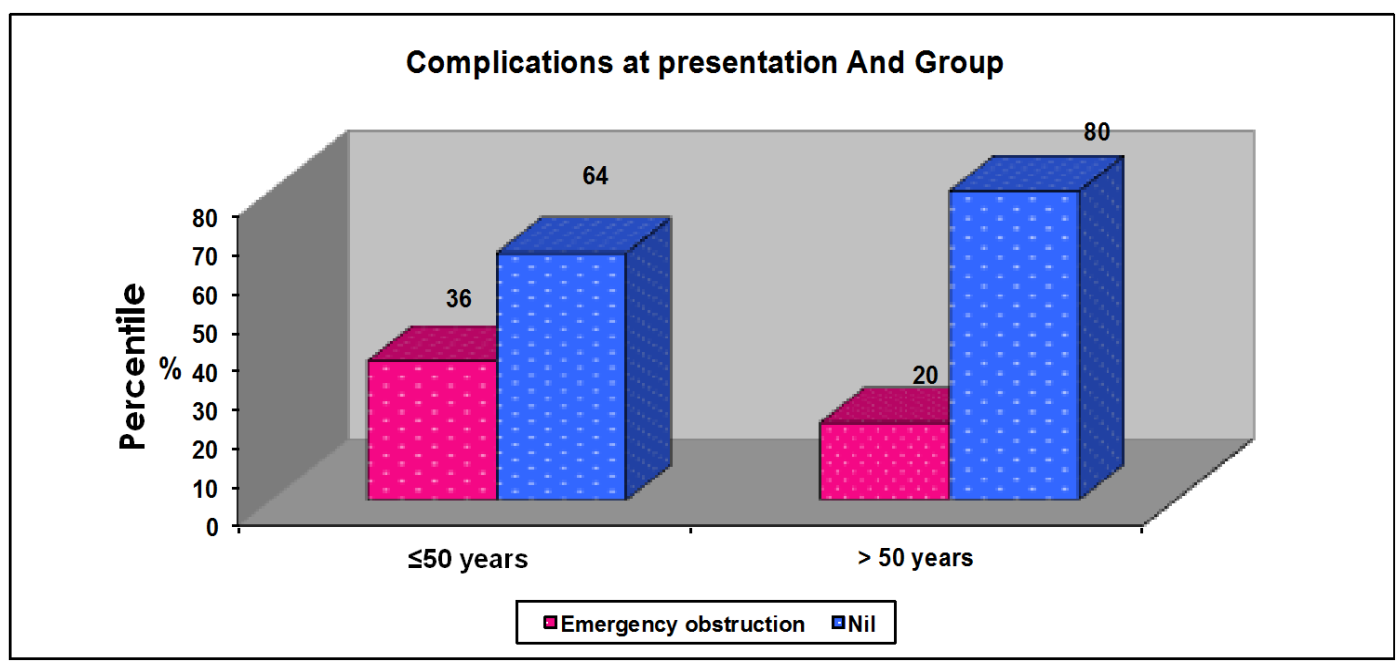

Figure 2.

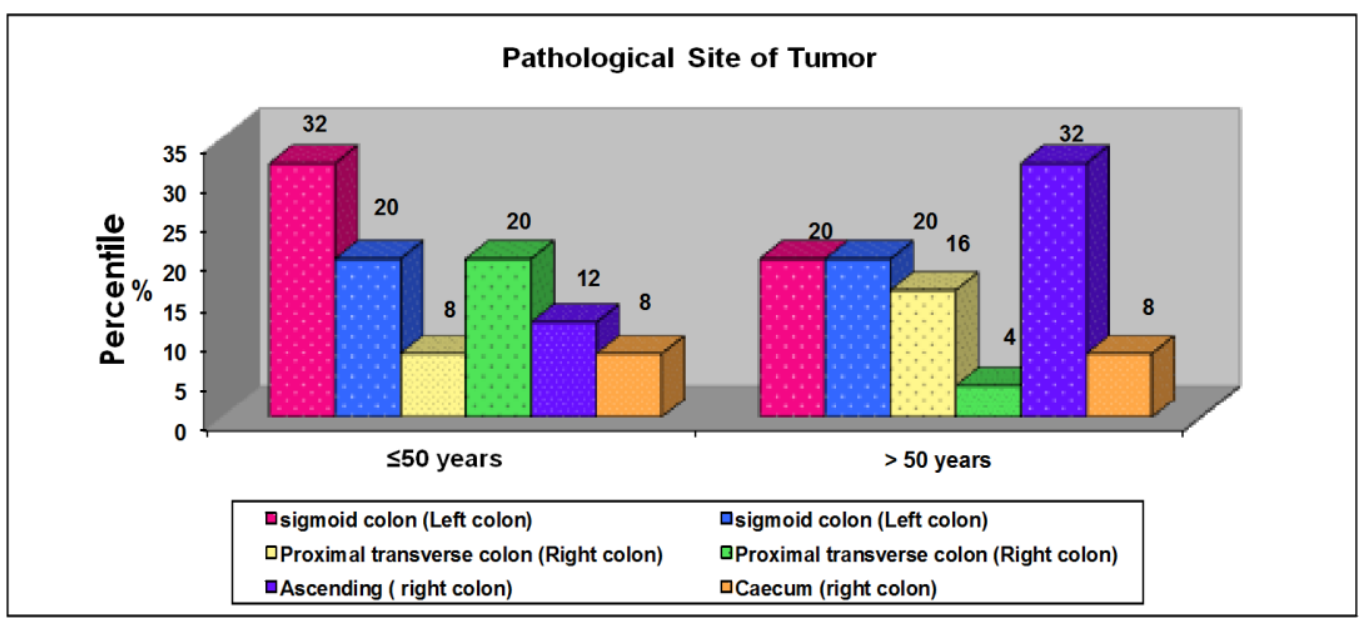


Table 2.

\begin{tabular}{|c|c|c|c|c|c|}
\hline & \multicolumn{2}{|c|}{ Group } & \multirow[b]{2}{*}{ Total } \\
\hline & & & $\leq 50$ Years & $>50$ Years & \\
\hline \multirow{6}{*}{$\begin{array}{l}\mathrm{HPE} \\
\text { grade }\end{array}$} & \multirow{2}{*}{$\begin{array}{l}\text { Low grade GI, well } \\
\text { differentiated }\end{array}$} & Count & 4 & 6 & 10 \\
\hline & & $\%$ within Group & $16.0 \%$ & $24.0 \%$ & $20.0 \%$ \\
\hline & \multirow{2}{*}{$\begin{array}{l}\text { GIII moderately } \\
\text { differentiated }\end{array}$} & Count & 10 & 14 & 24 \\
\hline & & $\%$ within Group & $40.0 \%$ & $56.0 \%$ & $48.0 \%$ \\
\hline & \multirow{2}{*}{$\begin{array}{l}\text { High grade, G III } \\
\text { poorly }\end{array}$} & Count & 11 & 5 & 16 \\
\hline & & $\%$ within Group & $44.0 \%$ & $20.0 \%$ & $32.0 \%$ \\
\hline \multirow[t]{2}{*}{ Total } & & Count & 25 & 25 & 50 \\
\hline & & $\%$ within Group & $100.0 \%$ & $100.0 \%$ & $100.0 \%$ \\
\hline
\end{tabular}

Figure 3.

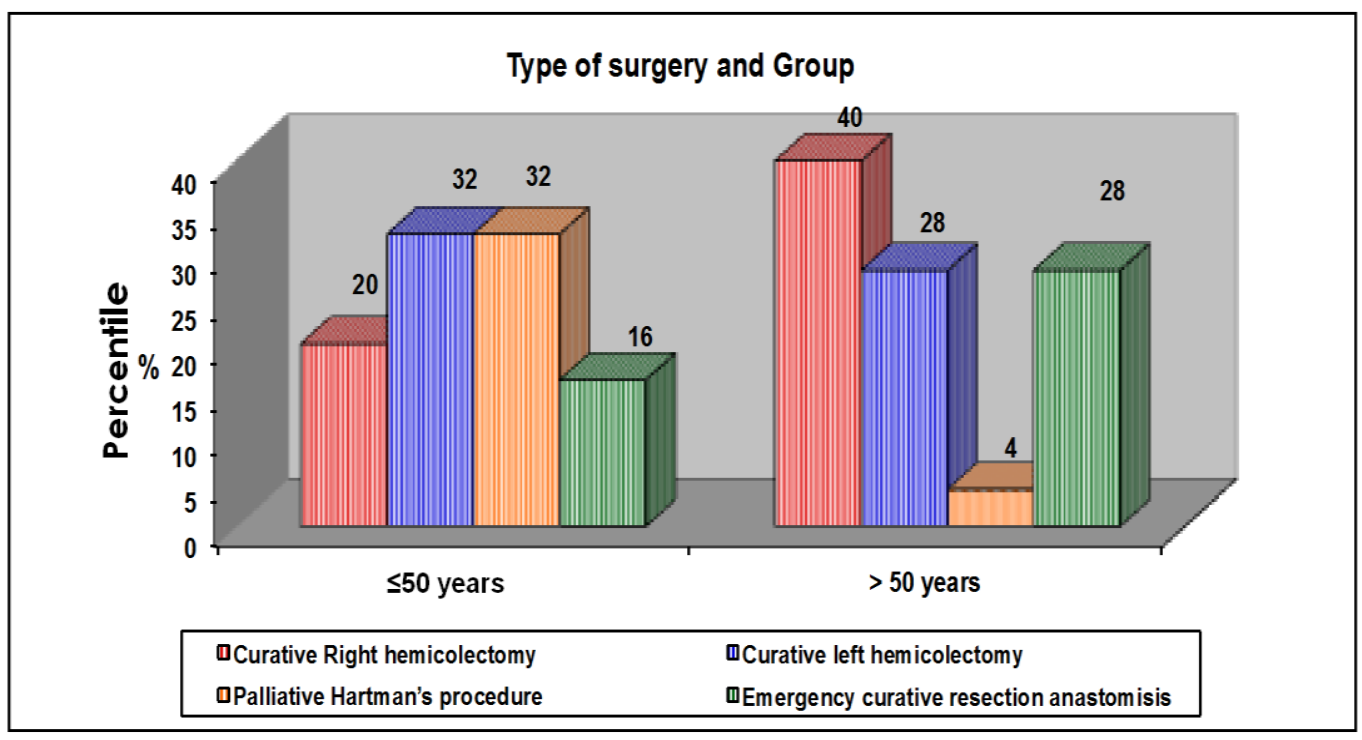

\section{Discussion}

In this study, there was male predominance, in the occurrence of the disease within both the groups. According to studies by Mohandas, K. M. et al and Peedikayil, Musthafa Chalikandy et al, it is shown that there is a slight increase in the incidence of the disease in males when compared to females in Indian population. ${ }^{(1,2)}$

In common to both groups, abdomen pain was the commonest symptom, and there was altered bowel habits more frequently seen in the older group. Myers, Elizabeth A., et al\& also by Ben-Ishay, Offir, et al also had similar finding on their study. ${ }^{(3,4)}$

There was a strong family history of the malignancy in patients belonging to the younger age group than the older group. This is in accordance to studies conducted by Chung, Y. F. A., et al\& also by Jarvinen, H. J. et al that a majority of the younger age group patients have significant family history. ${ }^{(5,6)}$

With respect to co-morbid factors, the older group tend to have medical ailments like Diabetes and hypertension. Studies by Giouleme, Olga et al have connected type $2 \mathrm{DM}$ and colo-rectal cancers, either proximal or distal, in both sexes. ${ }^{(7)}$ Additionally, chronic insulin treatment has been linked with increased risk of colo-rectal tumours among type 2 diabetic patients.

In this study, $36 \%$ of the patients in the $\leq 50$ age group presented with acute emergencies to the hospital, and in the above 50 age group $20 \%$ of 
the patient presented as emergencies. It is apparent that for reasons unknown yet, the younger age group patients present more acutely with emergencies than the older age group counterparts. This could probably be explained by the higher occurrence of poorly differentiated advanced malignancy in the younger age group.

Left sided malignancy were more common in the younger age group. Quah, H. M., et al\& also by Howard, E. W., et al had findings that showed younger patients present more with Left sided lesions. ${ }^{(8,9)}$ Younger age group had worse histology grade, presenting with more cases of poorly differentiated Grade III tumors in comparison to the older age group. This pattern of behavior of tumor in the younger age group has already been observed and reported by Ben-Ishay, Offir, et al\& also by Connell, Jessica B., et al. ${ }^{(4,10)}$ Adenocarcinoma was found to be the commonest variety of tumour consistent with other studies. Younger patients tend to present more with stage III and stage IV disease rather than stage I or II. Similar findings have been noted in other studies by Ben-Ishay, Offir, et al, Connell, Jessica B., et al and Chung, Y. F. A., et al. ${ }^{(4,5,10)}$

Studies byIsbister William $H$ et al \& also by O'Connell Jessica B., et al suggest that colonic cancer in the young population appears to be more aggressive, to present quickly, and to have poorer pathologic findings. ${ }^{(10,11)}$ However, if detected early, young patients have better overall 5-year survival rates. These findings emphasize the need for health care providers to have a heightened awareness when caring for this young population particularly because excellent modalities exist to diagnose and treat colorectal cancer.

\section{Conclusion}

This study shows certain different characteristics difference between the older and the younger group, but they did not significantly alter the disease progression or outcome. There was a frequent occurrence of high grade and advanced tumours in younger group, although the reasons for this discrepancies remain unclear, it could be due to environmental and genetic factors. Higher number of left sided malignancies in younger group were also reported in other studies. In our study, only factors significantly affected by age were tumour differentiation and site of tumour. Variable study designs on age differences in colon makes comparison difficult, and in addition, only fewer patients in the older group undergo surgery, hence selection bias cannot be excluded.

\section{Reference}

1. Mohandas, K. M.;Colorectal cancer in India: controversies, enigmas and primary prevention; Indian Journal of Gastroenterology 30.1 (2011): 3-6.

2. Peedikayil, Musthafa Chalikandy, et al.; Colorectal cancer distribution in 220 Indian patients undergoing colonoscopy.; Indian Journal of Gastroenterology28.6 (2009): 212-215.

3. Myers, Elizabeth A., et al.;Colorectal cancer in patients under 50 years of age: $A$ retrospective analysis of two institutions' experience.; World journal of gastroenterology: WJG 19.34 (2013): 5651.

4. Ben-Ishay, Offir, et al.’Diagnosis of colon cancer differs in younger versus older patients despite similar complaints"; The Israel Medical Association journal: IMAJ 15.6 (2013): 284-287.

5. Chung, Y. F. A., et al.; "Young age is not a poor prognostic marker in colorectal cancer"; British journal of surgery 85.9 (1998): 1255-1259.

6. Jarvinen, H. J., and M. J. Turunen. "Colorectal carcinoma before 40 years of age: prognosis and predisposing conditions"; Scandinavian journal of gastroenterology 19.5 (1984): 634-638.

7. Giouleme, Olga, Michael D. Diamantidis, and Marios G. Katsaros. "Is diabetes a causal agent for colorectal cancer? Pathophysiological and molecular mechanisms" World Journal of Gastroenterology: WJG 17.4 (2011): 444. 
8. Quah, H. M., et al. "Young age influences treatment but not outcome of colon cancer." Annals of surgical oncology 14.10 (2007): 2759-2765.

9. Howard, E. W., et al. "Colon and rectal cancer in the young adult." The American surgeon 41.4 (1975): 260.

10. O'Connell, Jessica B., et al. "Colorectal cancer in the young." The American journal of surgery 187.3 (2004): 343-348.

11. Isbister, William H. "Large-bowel cancer in the young: a national survival study." Diseases of the Colon \& Rectum 33.5 (1990): 363-366. 